\title{
DUODENAL ATRESIA - CASE STUDY
}

S.Smugreska1, M.Trencheva², V.Tasic ${ }^{3}$

1. Private Paediatric Practice "D-r Smugreska"

2. Private Paediatric Practice "D-r Trencheva"

3. University Children's Hospital, Nephrology Department

\section{Introduction:}

In our country, congenital anomalies rate in infants is $1,5 \%-2 \%$ per year. Most common are congenital anomalies and anomalies of GIT are on the third place. This case study shows an infant born with GIT anomaly - duodenal atresia.

\section{Aim:}

Necessity for prompt accurate diagnosis of duodenal atresia.

\section{Methods and materials:}

Case study of male infant, born in 2015, birth weight $3030 \mathrm{~g}$., height $50 \mathrm{~cm}$, born with vaginal delivery. After the birth there was significant reduction of birth weight and profuse vomiting. Native RTG was done and duodenal atresia was found. Surgery performed on Children's Surgical Clinic with anastomosis duodenojejunal. Further investigations: abdominal ultrasound without any significance.
Post-surgical status: Undefined leucocytosis and frequent visits to surgeon office. Biochemical investigations: Blood count, special colouring for morphology of Le domination of large lymphocytes and virocytes, Le - 22;18;23;16, Hb105;102;107 g/L, HCT - 30;31;31, \%MCV-70;75;73. Microbiology investigations: swab from throat, nose, ears, eyes - without any significance. Pneumoslide positive on mycoplasma pneumoniae, urine status normal, serological ELFA IGE total 26,9 KE/I. Child was hospitalized on Children's Clinic with diagnosis Respiratory Tract Infection, St. post duodenal atresia et anastomosis duodenojejunal with haematological investigations. Antibiotic therapy administered.

\section{Conclusion:}

Although surgical procedure was performed, persistent leucocytosis until 9 months has to be investigated. After that period, boy was with normal psycho motor development with regular checkups in paediatrician's office. 